\title{
Landscape-Scale Factors Affecting Feral Horse Habitat Use During Summer Within The Rocky Mountain Foothills
}

\author{
Tisa L. Girard • Edward W. Bork • \\ Scott E. Neilsen $\cdot$ Mike J. Alexander
}

Received: 25 June 2012/ Accepted: 2 November 2012/Published online: 27 November 2012

(C) Springer Science+Business Media New York 2012

\begin{abstract}
Public lands occupied by feral horses in North America are frequently managed for multiple uses with land use conflict occurring among feral horses, livestock, wildlife, and native grassland conservation. The factors affecting habitat use by horses is critical to understand where conflict may be greatest. We related horse presence and abundance to landscape attributes in a GIS to examine habitat preferences using 98 field plots sampled within a portion of the Rocky Mountain Forest Reserve of SW Alberta, Canada. Horse abundance was greatest in grassland and cut block habitats, and lowest in conifer and mixedwood forest. Resource selection probability functions and count models of faecal abundance indicated that horses preferred areas closer to water, with reduced topographic ruggedness, situated farther from forests, and located farther away from primary roads and trails frequented by recreationalists, but closer to small linear features (i.e. cut lines) that may be used as beneficial travel
\end{abstract}

\section{T. L. Girard · E. W. Bork ( $₫)$}

Department of Agricultural, Food and Nutritional Science, University of Alberta, 410 Agriculture/Forestry Center,

Edmonton, AB T6G 2P5, Canada

e-mail: edward.bork@ualberta.ca

T. L. Girard

e-mail: tlgirard@ualberta.ca

\section{S. E. Neilsen}

Department of Renewable Resources, University of Alberta,

751 General Services Building, Edmonton, AB T6G 2H1,

Canada

e-mail:scottn@ualberta.ca

\section{J. Alexander}

Alberta Environment and Sustainable Resource Development, Lands Division, Pincher Creek, AB, Canada

e-mail: mike.alexander@gov.ab.ca corridors. Horse presence and abundance were closely related to cattle presence during summer, suggesting that both herbivores utilise the same habitats. Estimates of forage biomass removal (44\%) by mid-July were near maximum acceptable levels. In contrast to horse-cattle associations, horses were negatively associated with wild ungulate abundance, although the mechanism behind this remains unclear and warrants further investigation. Our results indicate that feral horses in SW Alberta exhibit complex habitat selection patterns during spring and summer, including overlap in use with livestock. This finding highlights the need to assess and manage herbivore populations consistent with rangeland carrying capacity and the maintenance of range health.

Keywords Faecal counts - Forage biomass - Habitat selection - Human disturbance - Landscape characteristics . Thermal cover $\cdot$ Water availability

\section{Introduction}

Wild horses (Equus ferus) were well-established inhabitants of North America until extirpated more than 8,000 years ago (Lever 1985). Following re-introduction of the domestic horse (Equus ferus callabus) by Europeans, horses expanded in geographic range and eventually formed significant populations of free-ranging horses over large areas of the western United States and portions of Canada (Lever 1985; Singer 2005). Modern conservation of these animals depends on reliable information regarding the extent to which horses use different habitats across the landscape, together with the degree to which this selection may overlap with other land uses, including use by other herbivores. 
Public land in the Rocky Mountain Forest Reserve (RMFR) of southwestern Alberta, Canada, is managed for a suite of multiple uses, including biodiversity, wildlife management, cattle grazing, timber harvest, recreational activities, energy extraction and watershed protection (Government of Alberta 2010). Recent increases in the abundance of horses across this region from approximately 700 animals in 2006 to more than 1,000 animals in 2011 [Alberta Sustainable Resource Development (ASRD), unpublished data] have led to concerns over the availability of forage resources necessary to support existing land uses, including grazing by cattle, wildlife and feral horses. Competition among herbivores is particularly apparent in this region as grasslands occupy a small fraction of the landscape (i.e. $<5 \%$ by area), are known to be a critical resource for cattle (Kauffman 2011), and have declined in many regions due to ongoing shrub encroachment (Burkinshaw and Bork 2009). Decreases in grassland in turn, increase their vulnerability to degradation with overuse, symptomized by the loss of native plant species and increased invasive vegetation (Willms and others 1985).

Few previous studies have examined habitat use by feral horses, livestock and wildlife in this region, particularly during summer when overlap in habitat use is likely to be greatest. Using observational data, Salter and Hudson (1980) found horses used grasslands and open shrublands situated within valley bottoms during spring and early summer. Combined with grazing by cattle during midsummer (June 15-October 15), range condition has declined due to high forage use. Similarly, cattle are known to prefer grasslands in Montane ranges of southwest Alberta, particularly modified grasslands dominated by grazing tolerant invasive grasses (Kauffman 2011). Spatial overlap in the distribution of horses and cattle is expected within diverse landscapes as both species avoid steep slopes and rugged terrain, and instead congregate within valley bottoms (Ganskopp and Vavra 1987).

Dietary overlap between horses and cattle is likely to be high during the growing season (Salter and Hudson 1980; Shingu and others 2010), as both these herbivores prefer graminoids but utilise palatable forbs and shrubs when grasses become less available (Salter and Hudson 1979). Feral horses exhibit some dietary overlap with elk and moose, particularly during summer (Salter and Hudson 1980). Conversely, there is little overlap in the diets of horses and deer because the latter prefer browse (Hubbard and Hansen 1976), and horses use browse only when necessary.

Due to the increased possibility of habitat overlap among herbivores during summer, a better understanding is needed of the areas feral horses are utilising at that time, including mechanisms accounting for these patterns. Horses may preferentially exploit certain plant communities within the landscape because of herd socialisation (Kruger and Flauger 2008), changes in forage availability or quality (van Beest and others 2010) or physiological adaptations to extremes in topography (Holechek and others 2004). Socialisation plays an important role in regulating horse behaviour, with their gregarious nature leading to concentrated activity by harems. Physiological characteristics are also important as they determine nutritional needs. Horses are generally grazers with their adaptation as a hindgut fermentor allowing them to ingest large amounts of low quality forage when high quality forage is sparse (Janis 1976). Thus, horses make foraging decisions based on biomass over quality (Fleurance and others 2009).

It is also important to consider the impact of other landscape features on habitat selection by horses during summer, such as topography, elevation, solar radiation, distance to water, human activity and the abundance of competing herbivores. Investigating habitat use by horses in relation to these factors is particularly important in the RMFR given the high landscape diversity of the region. As feral horses, cattle and wildlife can occupy the same habitats during summer, management of horse populations and the associated rangeland resources they rely upon depends on a sound understanding of horse use patterns.

The objective of this study was to identify habitat use by feral horses using faecal counts taken from a network of field plots, and to identify landscape characteristics affecting habitat selection by feral horses. We hypothesized that horse presence would increase with forage availability, solar radiation and distance from human corridors, but decrease with increasing topographic ruggedness, distance from forest cover (i.e. shade) and distance to water. Finally, horse presence was hypothesized to decline with increasing abundance of competing cattle and native ungulates.

\section{Materials and Methods}

\section{Study Area}

This study was conducted in the McLean Creek Forest land use zone and adjacent area, located approximately $50 \mathrm{~km}$ southwest of Calgary, Alberta, Canada (Fig. 1). Landscapes in the area fall within the Montane and Subalpine natural subregions, with elevations ranging from 825 to $3,600 \mathrm{~m}$ (Natural Regions Committee 2006). Vegetation consists of a mosaic of sparse grasslands and riparian shrublands along valley bottoms, and widespread uplands comprised of mixedwood and conifer forests, or widely distributed conifer cutblocks (Willoughby and others 2005). Areas occupied by the different vegetation types from most to least abundant include conifer forests (69\% of area), conifer cutblocks (13\%), shrubland (9\%), mixedwood forest (4\%), 
Fig. 1 Feral horse study area in the Rocky Mountain Natural Region of SW Alberta
Bragg Creek

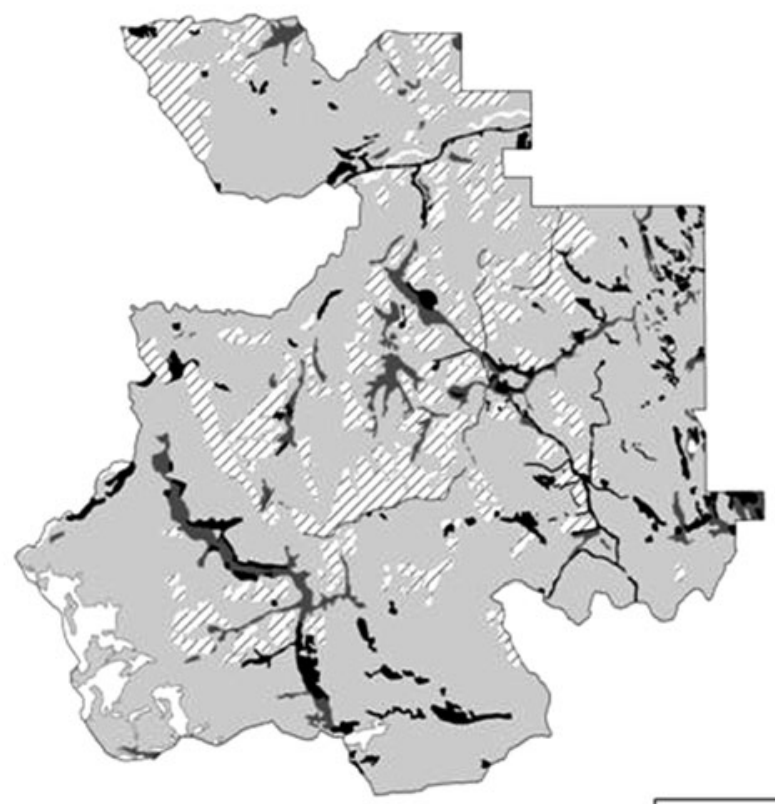

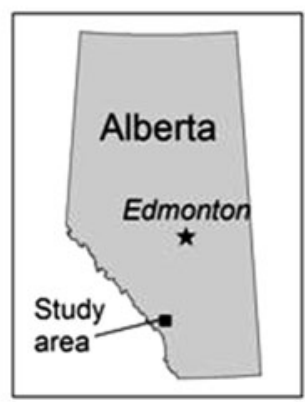

grassland $(4 \%)$ and water $(1 \%)$. Herbage production of communities varies widely, but is generally ranked as follows: grasslands $>$ shrublands $>$ conifer cutblocks $>$ mixedwood forests $>$ conifer forests (Willoughby and others 2005).

Feral horses have been present in Alberta since the early 1900's (Government of Alberta 2011) when surplus horses were released or abandoned. The Bragg Creek herd within the study area consists of 11 known harems and approximately 130 animals. Cattle graze this region from 15 June to 15 October under regulated grazing. Resident wildlife populations include moose, elk, mule and whitetail deer, as well as the occasional bighorn sheep. Predators in the area include wolves, cougars and black and grizzly bears.

Climate of the area is distinctly seasonal, with daily average temperatures at the nearby Elbow Ranger Station $\left(50.902^{\circ} \mathrm{N} ; 114.687^{\circ} \mathrm{W}\right)$ varying from $-9{ }^{\circ} \mathrm{C}$ in January to $12{ }^{\circ} \mathrm{C}$ in July and August (Environment Canada 2010). Annual precipitation for the region is $644 \mathrm{~mm}$, with the majority falling as rain during summer. Precipitation for both years of the study remained close to normal, although seasonal patterns of precipitation were dissimilar. In 2009, precipitation was below normal early in the growing season with a peak late in the summer, while in 2010 peak rainfall occurred a few months later than normal.

\section{Field Sampling}

Field data were collected from 5 to 11 August in 2009, and 10 to 24 July in 2010. Data were collected from 57 plots in 2009 and from the same 57, plus an additional 41 plots, in 2010. Plots were $4 \times 100 \mathrm{~m}$ in size, and distributed on a stratified random basis by watershed and habitat type. Plot locations were randomly placed in the field inside the boundaries of pre-selected plant communities, the latter of which were determined following an initial examination of aerial photos and field reconnaissance to ensure widespread distribution across the study area. All plot locations were determined using a GPS to facilitate relocation. In 2009, 12-13 plots were sampled in each habitat, except mixedwood forests $(n=8)$ due to the limited occurrence of this type. In 2010, 16-27 plots were sampled in each habitat with the exception of mixedwood forests $(n=9)$. 
Occupancy and abundance of different species of large herbivores (i.e. horses, cattle, elk, moose and deer) were quantified for each plot using pellet group counts collected along each $4 \mathrm{~m}$ wide belt transect. Only fresh and slightly decomposed pellet groups were recorded to ensure that they represented recent (e.g. spring or summer) activity. Pellets from the previous year and winter were easy to distinguish from recent activity, as the former had varying degrees of decomposition and weathering evident, and were typically associated with a greyish colouration. Field staffs conducting pellet counts were trained and familiar with the identification of faecal pellets from all large herbivores known to be in the study area.

All plots were assessed for forage availability (to the nearest $100 \mathrm{~kg} \mathrm{ha}^{-1}$ ) using ocular estimates of herbage (i.e. grasses and forbs combined). In addition, estimates were made on the proportion (i.e. \%) of current year's growth utilised. To validate our estimates of standing biomass, each year a subset of plots were sampled for current annual herbage and shrub biomass: 30 plots in 2009 and 55 plots in 2010, with a minimum of two plots sampled per habitat type. Within these plots, all current annual herbage was harvested to $2 \mathrm{~cm}$ height in a randomly placed $50 \times 50 \mathrm{~cm}\left(0.25 \mathrm{~m}^{2}\right.$ area $)$ subplot, and current annual browse up to $2 \mathrm{~m}$ height removed from shrubs and short trees $(<2 \mathrm{~m}$ tall) rooted in the quadrat. All biomass samples were dried to constant mass, weighed and converted to $\mathrm{kg} \mathrm{ha}^{-1}$ for analysis.

Initial correlation between ocular estimates of current annual biomass with actual biomass harvested from field plots indicated a reasonable fit in each of $2009\left(r^{2}=0.76\right.$; $P=0.09, n=30)$ and $2010\left(r^{2}=0.86 ; P<0.01, n=55\right)$. These findings support the notion that our ocular estimates were able to differentiate among areas containing varied forage availability. For our biomass values to adequately reflect the hypothesized influence of forage availability in regulating herbivore use, we used our corresponding estimates of forage use from each plot to model (i.e. back transform) available peak standing biomass in the absence of herbivory (see Eq. 1 below):

$$
\begin{aligned}
\text { Available biomass }= & \text { Estimated biomass }\left(\mathrm{kg} \mathrm{ha}^{-1}\right) \\
& \times 100 /[100-\text { Estimated use }(\%)]
\end{aligned}
$$

\section{Landscape Characterization of Plots}

Distances to landscape attributes were assessed for each plot centre using the Euclidean Distance tool in ArcGIS 9.3 (ESRI 2009). GIS predictors included roads, recreational backcountry trails, cutlines (i.e. seismic trails associated with energy exploration), major water sources, vegetation types, and a digital elevation model (DEM). Conifer and mixedwood forest habitat types were combined to create an aggregate forest cover class variable, with minimum distance to cover determined for all plots not in forests. A DEM was used to generate terrain-related landscape factors including terrain ruggedness (Riley and others 1999) and solar radiation (Kumar and others 1997) for 21 March.

\section{Statistical Analysis}

All independent variables were tested for redundancy using Proc CORR in SAS 9.2. For variables correlated at $|r|>0.7$, the variable most representative of others and with the greatest interpretive value was retained for analysis. As a result of this procedure, we used only ruggedness, distance to all forests and distance to water, in the analysis of landscape attributes. Similarly, as wild ungulates comprised the minority of observed pellet counts (10\% of all counts), we combined those data into a single wild ungulate response variable.

Variations in actual biomass (from clips), estimated biomass, biomass utilisation and total available standing biomass (i.e. after back-transformation), were compared among habitat types using an ANOVA performed in Proc MIXED of SAS. All variables were tested for normality and equality of variances using a Shapiro-Wilks and Levene's test, respectively. Biomass values were natural log transformed. Habitat type and year were fixed in the analysis, with plots random. Post-hoc mean comparisons on all responses with significant effects were compared using an adjusted Tukey test, based on $P<0.05$. All analyses used LSmeans.

Approximate utilisation by each ungulate group was assessed by determining the relationship between pellet counts, biomass availability, and estimated biomass utilisation. Relationships were assessed through Pearson correlations (Proc CORR, SAS 9.2) at $P<0.05$.

\section{Resource Selection Probability Functions}

Resource selection probability functions (RSPFs) quantify how animals select specific areas of the landscape (Manly and others 2002). This study was a Type I design (Manly and others 2002) investigating resource selection at the level of the population based on used versus unused observations. Forage biomass and landscape attributes (i.e. ruggedness, solar radiation and distance to forest, water and travel corridors), together with indicates of cattle and native ungulate presence and abundance, were employed to develop RSPFs for feral horses based on pellet count densities.

Competing models were used to test whether factors considered important for altering animal use (a priori hypotheses) affected habitat selection by horses. Predictor 
variables were divided into various ecological "themes" representing contrasting environmental requirements of feral horses (Table 1). Selection was hypothesized to specifically increase with (1) greater forage availability, (2) reduced distance to water, (3) decreased ruggedness of the landscape, (4) decreased radiation and decreased distance to shade in forest (i.e. assuming horses strive to avoid summer heat), (5) decreased distance to cutlines (i.e. ready travel routes), but increased distance from roads and trails (to avoid disturbance from recreationalists), and (6) decreased abundance of other herbivores.

Pellet count data were tested for over-dispersion due to the abundance of zeros (Vaudor and others 2011), by determining the ratio of variance to mean pellet counts. Values greater than one indicate dispersion, and were tested using Proc COUNTREG in SAS 9.2. As the horse data were found to be over-dispersed, $-2 \log$ likelihoods (-2LL) were determined through zero-inflated poisson (ZIP) regression (Barry and Welsh 2002; Nielsen and others 2005; Vaudor and others 2011), using Proc COUNTREG and Proc GENMOD in SAS 9.2. Resulting over-dispersion (alpha) estimates differed from zero and indicated that the zero-inflated models were better than their non-zero counterparts (SAS Institute Inc. 2011). Zero-inflated count models divide data into an always zero group (zeromodel) and a not always zero group (Nielsen and others 2005).

To determine the zero model, the -2LL was obtained using logistic regression in Proc LOGISTIC in SAS 9.2. Akaike information criteria (AIC), corrected for small sample sizes $\left(\mathrm{AIC}_{\mathrm{c}}\right)$, was used to rank models within ecological themes (see Eq. 2).

$$
\begin{aligned}
\mathrm{AIC}_{\mathrm{c}}= & -2 \mathrm{LL}+2 k(\# \text { of parameters }) \\
& +2 k(k+1) /(n(\text { sample size })-k-1)
\end{aligned}
$$

Models were compared against one another within the individual themes of forage characteristics, water and topography, disturbance, thermal factors, and competition, with the lowest $\mathrm{AIC}_{\mathrm{c}}$ score subtracted from the other $\mathrm{AIC}_{\mathrm{c}}$ scores to provide the $\Delta \mathrm{AIC}_{\mathrm{c}}$ (see Eq. 3).

$\Delta \mathrm{AIC}_{\mathrm{c}}=\mathrm{AIC}_{\mathrm{ci}}-\mathrm{AIC}_{\mathrm{cmin}}$

Within each theme, the model with the lowest $\mathrm{AIC}_{\mathrm{c}}$ was moved forward to the final analysis where all leading variables from each theme were combined in an additive fashion (i.e. added sequentially in descending order according to their $-2 \mathrm{LL}$ ). Once the $\mathrm{AIC}_{\mathrm{c}}$ analysis was complete, the final model with the lowest $\Delta \mathrm{AIC}_{\mathrm{c}}$ was considered the best zero-count model.

Second, the ZIP model was estimated to explain the relative abundance of ungulates when present. The $\mathrm{AIC}_{\mathrm{c}^{-}}$ selected zero-count model was fit for the ZIP model and the same themes tested and ranked using $\mathrm{AIC}_{\mathrm{c}}$. Different variables were combined in an additive fashion for the final analysis to determine the best overall model. Final model selection was based on the lowest $\Delta \mathrm{AIC}_{\mathrm{c}}$, which was considered to be the best model explaining horse presence and abundance (faecal counts). Model probabilities $\left(\omega_{\mathrm{i}}\right)$ were calculated to quantify the probability of each model being the best model (see Eq. 4).

$\omega_{\mathrm{i}}=\exp \left(-0.5 \Delta_{\mathrm{i}}\right) / \sum \exp \left(-0.5 \Delta_{\mathrm{r}}\right)$

To determine the amount of variation described by each model, $-2 \mathrm{LL}$ values were used to generate a pseudo $R^{2}$ (goodness-of-fit) to compare the percentage of deviance explained by all models in comparison to a null model (Cameron and Windmeijer 1997; Windmeijer 1995) (see Eq. 5).

Table 1 Description of variables by theme used in the assessment of feral horse resource selection

\begin{tabular}{lll}
\hline Variable & Theme & Description \\
\hline Forage & Adj. biomass & Adjusted biomass through back-transformation $\left(\mathrm{kg} \mathrm{ha}^{-1}\right)$ \\
Water and topography & D. water & Distance of horse/random points to nearest source of water $(100 \mathrm{~m}$ increments $)$ \\
Water and topography & TRI & Terrain ruggedness index, increasing values indicate increasing landscape roughness \\
Disturbance & D. roads/trails & Distance of horse/random points to nearest road or trail $(100 \mathrm{~m}$ increments $)$ \\
Disturbance & D. cutlines & Distance of horse/random points to the nearest cutline $(100 \mathrm{~m}$ increments $)$ \\
Thermal & D. mixedwood & Distance of horse/random points to the nearest mixedwood forest $(100 \mathrm{~m}$ increments) \\
Thermal & D. conifer & Distance of horse/random data points to the nearest conifer forest $(100 \mathrm{~m}$ increments $)$ \\
Thermal & D. any forest & Distance of horse/random data points to nearest forest $(100 \mathrm{~m}$ increments) \\
Thermal & DSR & Diffuse solar radiation. Measure of scattered wavelengths on March 21 \\
Thermal & GSR & Global solar radiation. Measure of shortwave + diffuse radiation \\
Competition & Cattle & Pellet density of cattle within the same plot \\
Competition & Ungulates & Pellet density of wild ungulates within the same plot \\
\hline
\end{tabular}

Variables include spatial and habitat type data 
McFadden's pseudo $R^{2}$

$=1-(\log$ likelihood candidate model $/$

log likelihood null model)

Finally, since data were overdispersed, the presence/ absence models in the form of RSPFs (Manly and others 2002) were developed using the beta estimates from the zero-inflated models to quantify relationships between horse occurrence and landscape characteristics (see Eq. 6).

$$
\begin{aligned}
\mathrm{RSPF}= & \exp \left(\beta_{\mathrm{o}}+\beta_{1} x_{1}+\ldots+\beta_{p} x_{p}\right) / 1 \\
& +\exp \left(\beta_{\mathrm{o}}+\beta_{1} x_{1}+\ldots+\beta_{\mathrm{p}} x_{\mathrm{p}}\right)
\end{aligned}
$$

In addition, count models were developed based on the $\beta$ estimates for the Poisson model factors (Eq. 7).

Count model $=\exp \left(\beta_{1} x_{1}+\ldots+\beta_{\mathrm{p}} x_{\mathrm{p}}\right)$

Beta $(\beta)$ coefficients were obtained from the Proc COUNTREG (SAS 9.2) output to obtain the -2LL and provide the directionality and magnitude of the association between horse presence or abundance and the independent factors examined.

\section{Results}

Forage Characteristics and Utilisation Trends Among Habitats

Grasslands and shrublands had the greatest availability of grass biomass, followed by cutblocks and mixedwood forests, with little grass biomass available in conifer forests (Table 2). Forb biomass remained similar across most habitats, with the exception of conifer forest where it was particularly low. Shrub biomass was greatest in shrublands, followed by conifer forest: cutblocks, mixedwood forest and grasslands had relatively little shrub biomass.

Analysis of pellet counts among habitats indicated that horse presence was lower in mixedwood and conifer forest relative to all other types (Table 2). Similar to horses, cattle had the greatest presence in grassland, with the intermediate presence in shrublands, cutblocks and mixedwood forest, and very little use in conifer forest. Unlike horses or cattle, wild ungulate presence was greatest in conifer forest, intermediate in shrublands and uncommon in the remaining three habitats. Biomass utilisation at mid-summer sampling was greatest in grasslands, and progressively declined through shrublands, cutblocks and mixedwood forest, with almost no use in conifer forest (Table 2). Utilisation estimates were positively associated with both horse $(r=+0.55 ; P<00.001)$ and cattle $(r=+0.71$; $P<0.001)$ pellet count densities, but were negatively associated with wild ungulates $(r=-0.59 ; P<0.001)$.

\section{Resource Selection: Zero-Count Models}

Initial a-priori models used to test for the presence of feral horses and develop zero-count models identified similar factors of importance within each ecological theme in both 2009 and 2010. While adjusted herbage biomass represented forage characteristics, distance to roads and trails was the most important disturbance factor in both years. For competition factors, pellet counts of competing ungulates were identified. For water and topography, ruggedness was the most important factor in 2009, while distance to water was the most important factor in 2010. Important thermal factors included solar radiation in 2009 and distance to forest 1 year later.

During 2009, the individual variables that explained the most deviance in horse occupancy were ranked in descending order as follows: thermal $>$ disturbance $>$ competition $>$ water and topography $>$ forage biomass. The final zero-count model for 2009 was the thermal model, explaining $5.8 \%$ variance in horse pellet presence and a $0.48(48 \%)$ probability of being the best model among those tested (Table 3 ). According to the resulting beta $(\beta)$

Table 2 Mean pellet counts, total utilisation and standing biomass values for various habitat types in the Rocky Mountain Forest Reserve of

\begin{tabular}{|c|c|c|c|c|c|c|c|}
\hline \multirow[t]{2}{*}{ Habitat } & \multicolumn{3}{|c|}{ Pellet count density (\# $400 \mathrm{~m}^{-2}$ ) } & \multirow{2}{*}{$\begin{array}{l}\text { Utilisation (\%) } \\
\text { Total }\end{array}$} & \multicolumn{3}{|c|}{ Biomass $\left(\mathrm{kg} \mathrm{ha}^{-1}\right)$} \\
\hline & Horse & Cattle & Wild ungulates & & Grass & Forb & Shrub \\
\hline Conifer forest & $1.0 \mathrm{~b}^{\mathrm{a}}$ & $1.0 \mathrm{c}$ & $4.0 \mathrm{a}$ & $3.1 \mathrm{c}$ & $42 \mathrm{~d}$ & $107 \mathrm{c}$ & $263 \mathrm{~b}$ \\
\hline Conifer cutblock & $5.6 \mathrm{a}$ & $4.2 \mathrm{bc}$ & $0.6 \mathrm{c}$ & $21.5 \mathrm{ab}$ & $645 \mathrm{bc}$ & $455 \mathrm{ab}$ & $104 \mathrm{c}$ \\
\hline Grassland & $6.0 \mathrm{a}$ & $35.9 \mathrm{a}$ & $0.1 \mathrm{c}$ & $43.5 \mathrm{a}$ & $1140 \mathrm{a}$ & $612 \mathrm{a}$ & $0 \mathrm{~d}$ \\
\hline Mixedwood forest & $1.0 \mathrm{~b}$ & $4.8 \mathrm{bc}$ & $0.8 \mathrm{c}$ & $12.4 \mathrm{~b}$ & $362 \mathrm{c}$ & $292 \mathrm{bc}$ & $46.7 \mathrm{~cd}$ \\
\hline Riparian shrubland & $2.3 \mathrm{ab}$ & $14.6 \mathrm{ab}$ & $2.6 \mathrm{~b}$ & $20.0 \mathrm{ab}$ & $871 \mathrm{ab}$ & $459 \mathrm{~b}$ & $732 \mathrm{a}$ \\
\hline Std. error & \pm 1.2 & \pm 5.6 & \pm 0.5 & \pm 4.5 & \pm 154 & \pm 84 & \pm 90 \\
\hline
\end{tabular}
Alberta for the summer of 2009 and 2010 combined

${ }^{a}$ Within a column, means with different letters differ, $P<0.05$ 
coefficient, horse occupancy increased as solar radiation increased (Table 4). During 2010, the ranking of individual themes changed as follows: competition $>$ disturbance $>$ biomass $>$ thermal $>$ water and topography. The best zerocount model for 2010 was the model combining disturbance and competition, which explained $6.9 \%$ of variance in horse pellet presence, and had a $0.52(52 \%)$ probability of being the best model (Table 3). According to the $\beta$ coefficients, horse occupancy increased farther from roads and trails but decreased as wild ungulate presence increased (Table 4).

\section{Resource Selection: Abundance Models}

Initial a-priori ZIP models from 2009 indicated that all but three variables (distance to roads and trails, cattle pellet counts and solar radiation) were suitable for inclusion in the final comparative analysis. Consequently, variables used to estimate feral horse abundance were adjusted biomass, ruggedness, water distance, ungulate pellet counts and the distance to both cutlines and forest. Variance in horse abundance explained by the 2009 variables was ranked as follows (from most important to least important): water and topography $>$ competition $>$ disturbance $>$ thermal $>$ forage biomass.

During 2010, the variables selected from the individual themes differed slightly from the year before. In addition to biomass from the forage theme, water distance and ruggedness were both selected within the water and topography theme. Distance to roads/trails as well as cutlines, were selected as the most important factors from the disturbance theme. Distance to forest and solar radiation variables were both important in the thermal theme, while cattle and ungulate pellet counts were used for the competition theme. Rankings among variables in 2010 were similar to the year prior, with one notable change in that water and topography moved from being the most important to the least important: competition $>$ disturbance $>$ thermal $>$ forage biomass $>$ water and topography.

Table 3 Summary results of the final model analysis depicting comparative model strength of predictive horse occupancy (i.e. presence) from field plot data collected during the summer of 2009 or 2010, and various landscape attributes

\begin{tabular}{|c|c|c|c|c|c|c|}
\hline Ranked model themes & $R^{2 \mathrm{a}}$ & $k^{\mathrm{b}}$ & $-2 L L^{c}$ & $\mathrm{AIC}_{\mathrm{c}}{ }^{\mathrm{d}}$ & $\Delta \mathrm{AIC}_{\mathrm{c}}{ }^{\mathrm{e}}$ & $\omega_{\mathrm{i}}^{\mathrm{f}}$ \\
\hline \multicolumn{7}{|l|}{$2009^{\mathrm{g}}$} \\
\hline Null $^{\mathrm{h}}$ & 0.00 & 1 & 78.86 & 80.93 & 2.45 & 0.14 \\
\hline Thermal & 5.83 & 2 & 74.26 & 78.48 & 0.00 & 0.48 \\
\hline Thermal + disturbance & 7.14 & 3 & 73.23 & 79.68 & 1.20 & 0.26 \\
\hline Thermal + disturbance + water and topography & 7.16 & 4 & 73.21 & 81.98 & 3.50 & 0.08 \\
\hline Thermal + disturbance + water and topography + competition & 7.61 & 5 & 72.86 & 84.04 & 5.55 & 0.03 \\
\hline Thermal + disturbance + water and topography + competition + forage & 7.65 & 6 & 72.83 & 86.51 & 8.03 & 0.01 \\
\hline \multicolumn{7}{|l|}{$2010^{\mathrm{i}}$} \\
\hline Null $^{\mathrm{h}}$ & 0.00 & 1 & 135.49 & 137.56 & 4.92 & 0.04 \\
\hline Competition & 3.80 & 2 & 130.34 & 134.56 & 1.92 & 0.20 \\
\hline Competition + disturbance & 6.86 & 3 & 126.19 & 132.64 & 0.00 & 0.52 \\
\hline Competition + disturbance + forage & 6.89 & 4 & 126.16 & 134.93 & 2.29 & 0.17 \\
\hline Competition + disturbance + forage + thermal & 6.95 & 5 & 126.08 & 137.26 & 4.61 & 0.05 \\
\hline Competition + disturbance + forage + thermal + water and topography & 7.43 & 6 & 125.42 & 139.10 & 6.46 & 0.02 \\
\hline
\end{tabular}

Bolded and italicized models indicate the best model for each year

a McFadden's pseudo $R^{2}$ goodness-of-fit measure

b Number of model parameters

c $-2 \log$ likelihood

d AIC corrected for sample size of 57 observations in 2009 and 98 observations in 2010

e Difference between $\mathrm{AIC}_{\mathrm{c}}$ value and the lowest $\mathrm{AIC}_{\mathrm{c}}$ value within each theme

${ }^{\mathrm{f}}$ Model probability

g In 2009, the thermal, disturbance, water and topography, competition and forage themes were represented by global solar radiation, distance to roads/trails, ruggedness, ungulate pellet count, and adjusted forage biomass, respectively

h Null model with intercept only

${ }^{i}$ In 2010, the disturbance, forage, thermal, water and topography and competition themes were represented by distance to roads/trails, adjusted forage biomass, distance to forest, distance to water and ungulate pellet count, respectively 
Table 4 Influence of different variables selected by AIC modelling on feral horse occupancy and abundance from logistic regression (occupancy) and zero-inflated poisson regression (abundance) in the Alberta foothills during the summer of 2009 and 2010

\begin{tabular}{lclc}
\hline Response and variable & $\beta$ coefficient & Std. error & $P$-value \\
\hline $\mathbf{2 0 0 9}$ & & & \\
Occupancy & & & \\
$\quad$ Solar radiation & 0.000367 & 0.00018 & 0.046 \\
Abundance & & & \\
$\quad$ Distance to water & 0.004 & 0.001 & 0.0001 \\
$\quad$ Ruggedness & -0.077 & 0.027 & 0.10 \\
$\quad$ Wild ungulates & -0.190 & 0.079 & 0.01 \\
$\mathbf{2 0 1 0}$ & & & \\
Occupancy & & & \\
$\quad$ Distance to roads and trails & 0.0007 & 0.00076 & 0.06 \\
$\quad$ Wild ungulates & -0.202 & 0.096 & 0.04 \\
Abundance & & & \\
Cattle & 0.004 & 0.002 & 0.05 \\
$\quad$ Wild ungulates & -0.105 & 0.059 & 0.07 \\
$\quad$ Distance to roads and trails & -0.0006 & 0.0001 & $<0.0001$ \\
$\quad$ Distance to cutlines & -0.003 & 0.0006 & $<0.0001$ \\
Distance to any forest & 0.008 & 0.002 & $<0.0001$ \\
Solar radiation & 0.0001 & 0.000 & 0.003 \\
Distance to water & -0.002 & 0.0006 & 0.09 \\
Ruggedness & -0.036 & 0.016 & 0.02 \\
\hline
\end{tabular}

\section{Final Resource Selection Models}

Final AIC analysis of the 2009 feral horse occupancy and abundance data indicated that the "water and topography plus competition" model was the best integrated model (Table 5). Variables included were distance to water, ruggedness and wild ungulate presence, which together explained $10.2 \%$ of variance in horse pellet counts and had a $0.46(46 \%)$ probability of being the best model (Table 5). In 2010, the best supported model was the "competition plus disturbance plus thermal plus water and topography" model (Table 5). Specific variables included in this model were distance to water, ruggedness, distance to both roads/trails and cutlines, distance to forest, solar radiation and both cattle and ungulate pellet counts. This combination of variables explained $22.6 \%$ of the variance in horse pellet counts and had a $0.76(76 \%)$ probability of being the best model (Table 5).

The $\beta$ estimates for 2009 indicated that as distance to water increased, the probability of horse use increased (Table 4). In 2010, $\beta$ estimates for water indicated a different relationship, with horse use declining as distance to water increased. In both years, there was an inverse relationship between terrain ruggedness and horse use, although this was further affected by water availability during 2009 (Fig. 2).

The $\beta$ estimates indicating the effects of wild ungulates on horses in both 2009 and 2010 revealed a negative relationship between species (as ungulates increased, horse use decreased; Fig. 3). The opposite relationship was observed for cattle, however, as cattle and horse use demonstrated a distinct parallel trend (Table 4; Fig. 4). For the disturbance variables in 2010 , probability of horse use decreased with increasing distance to either roads/trails or cutlines (Table 4; Fig. 4). Finally, horse use was positively related to distance from forest and solar radiation (Fig. 5).

\section{Discussion}

Our results considered both coarse landscape-level selection patterns of horse use through RSPF analyses (presence/ absence) and patterns of horse abundance where present. Increased horse occupancy in plots with greater solar radiation in 2009 suggests horses do not seek shade in this landscape, and instead prefer areas with greater sun exposure. Although areas with greater radiation may be warmer and therefore attract horses, a more likely explanation is that these areas may have greater herbage growth (Willoughby and others 2005), particularly as sparse Montane grasslands are more likely to be found on south-facing slopes in this area, thereby offering improved foraging opportunities (Fleurance and others 2009). In addition, warmer spring temperatures may accelerate vegetative growth (Willoughby and others 2005), and hence attract horses to utilise them earlier in the year.

Our finding that horse use was positively related to distance to forest edge results in the rejection of our hypothesis that horses prefer forest edges. While horses are known to use forests for shade in summer (Mysterud and Østbye 1999), this did not occur in our investigation. Shade may not be important for horses in this region as maximum daytime temperatures rarely exceeded $30^{\circ} \mathrm{C}$. Horses may also be avoiding forest edges as an adaptive strategy to minimize predation risk, particularly from cougars which are a significant risk in the area (Knopff 2010).

Horses preferred to occupy areas farther from roads and trails during 2010, and is consistent with our hypothesis that horses avoid human travel corridors. These findings contrast those of the count models from that year however, where horses preferred areas closer to linear corridors. This dichotomy can be explained by differences in the scale these models effectively represent within our study area. The McLean Creek recreational area is a popular region for backcountry recreation, and receives high human traffic during summer. Horses may be avoiding major roads and primary recreational trails in an effort to minimize contact 
Table 5 Summary results of the final combined model analysis depicting comparative model strength of zero-inflated poisson (ZIP) models reflecting horse presence and abundance from field plot data collected during the summer of 2009 or 2010, and various landscape attributes

\begin{tabular}{|c|c|c|c|c|c|c|}
\hline Ranked model themes & $R^{2 \mathrm{a}}$ & $k^{\mathrm{b}}$ & $-2 L L^{c}$ & $\mathrm{AIC}_{\mathrm{c}}{ }^{\mathrm{d}}$ & $\Delta \mathrm{AIC}_{\mathrm{c}}{ }^{\mathrm{e}}$ & $\omega_{\mathrm{i}}^{\mathrm{f}}$ \\
\hline \multicolumn{7}{|l|}{$2009^{g}$} \\
\hline Null $^{\mathrm{h}}$ & 0.00 & 1 & 220.20 & 222.27 & 15.78 & 0.00 \\
\hline Water and topography & 7.22 & 3 & 204.30 & 210.75 & 4.26 & 0.05 \\
\hline Water and topography + competition & 10.21 & 4 & 197.72 & 206.49 & 0.00 & 0.46 \\
\hline Water and topography + competition + disturbance & 10.21 & 5 & 197.72 & 208.90 & 2.41 & 0.14 \\
\hline Water and topography + competition + disturbance + thermal & 11.88 & 6 & 194.04 & 207.72 & 1.23 & 0.25 \\
\hline Water and topography + competition + disturbance + thermal + forage & 12.20 & 7 & 193.34 & 209.63 & 3.14 & 0.10 \\
\hline \multicolumn{7}{|l|}{$2010^{\mathrm{i}}$} \\
\hline $\mathrm{Null}^{\mathrm{h}}$ & 1.00 & 1 & 499.20 & 501.27 & 86.68 & 0.00 \\
\hline Competition & 7.81 & 3 & 464.86 & 471.31 & 56.72 & 0.00 \\
\hline Competition + disturbance & 15.38 & 5 & 426.68 & 437.86 & 23.27 & 0.00 \\
\hline Competition + disturbance + thermal & 20.40 & 7 & 401.4 & 417.69 & 3.10 & 0.05 \\
\hline Competition + disturbance + thermal + forage & 20.50 & 8 & 400.90 & 419.90 & 5.31 & 0.02 \\
\hline Competition + disturbance + thermal + water and topography & 22.59 & 9 & 390.34 & 412.17 & 0.00 & 0.76 \\
\hline Competition + disturbance + thermal + forage + water and topography & 22.59 & 10 & 390.34 & 415.124 & 0.53 & 0.17 \\
\hline
\end{tabular}

Bolded and italicized models indicate the best model

a McFadden's pseudo $R^{2}$ goodness-of-fit measure

b Number of model parameters

c $-2 \log$ likelihood

d AIC corrected for sample size of 57 observations in 2009 and 98 observations in 2010

e Difference between $\mathrm{AIC}_{\mathrm{c}}$ value and the lowest $\mathrm{AIC}_{\mathrm{c}}$ value within each theme

${ }^{\mathrm{f}}$ Model probability

g In 2009, the water and topography, competition, disturbance, thermal and forage themes are represented by water distance and ruggedness, ungulate pellet count, distance to cutlines, distance to forest and adjusted forage biomass, respectively

h Null model with intercept only

${ }^{i}$ In 2010, the competition, disturbance, thermal, forage and water and topography themes are represented by cattle and ungulate pellet counts, distance to roads/trails and cutlines, distance to forest and global solar radiation, adjusted forage biomass, and water distance and ruggedness, respectively

Fig. 2 Horse count models demonstrating the relationship between horse abundance in 2009 (circle) and 2010 (square), as influenced by three distances to water $[150,300$ and $450 \mathrm{~m}$ in 2009; $300 \mathrm{~m}$ in 2010 (due to curve similarities)] and increasing terrain ruggedness. Functions were developed with $\beta$ coefficients derived from the best model using ZIP regression, with other variables not included held constant

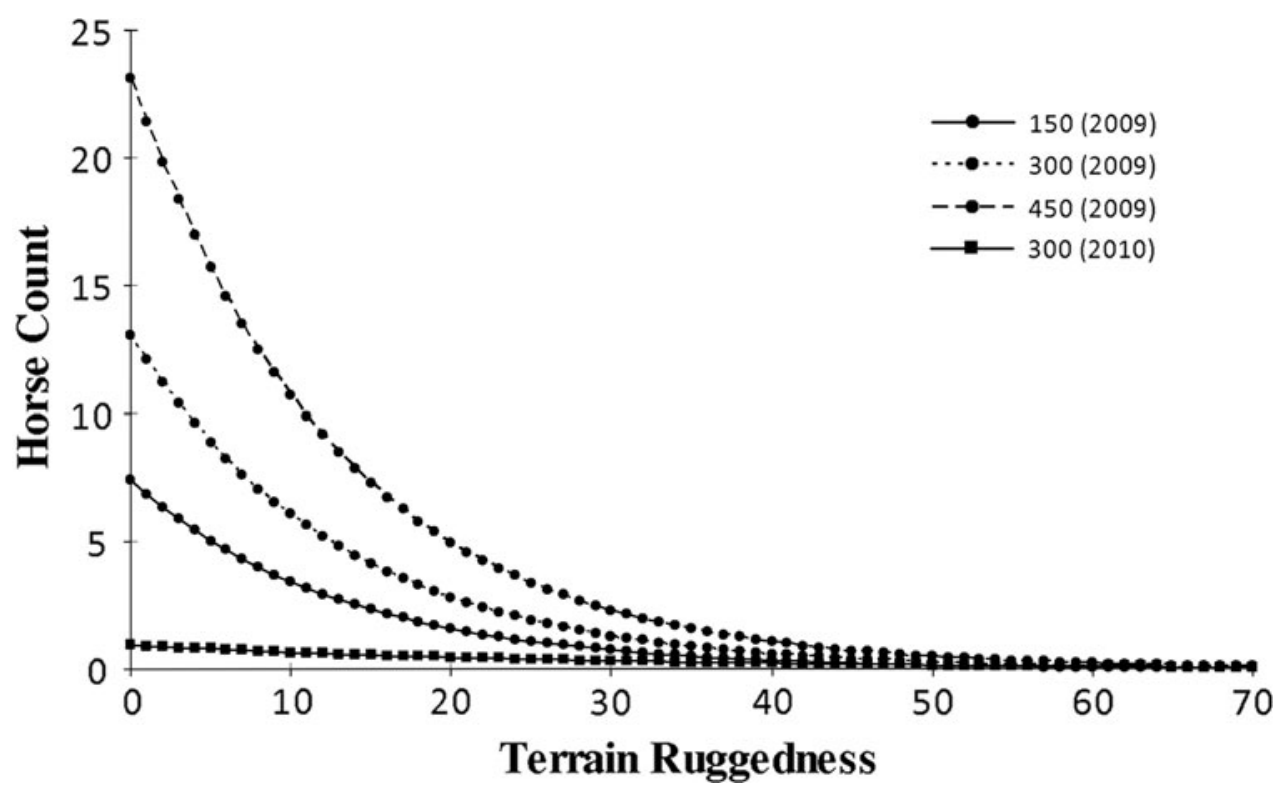




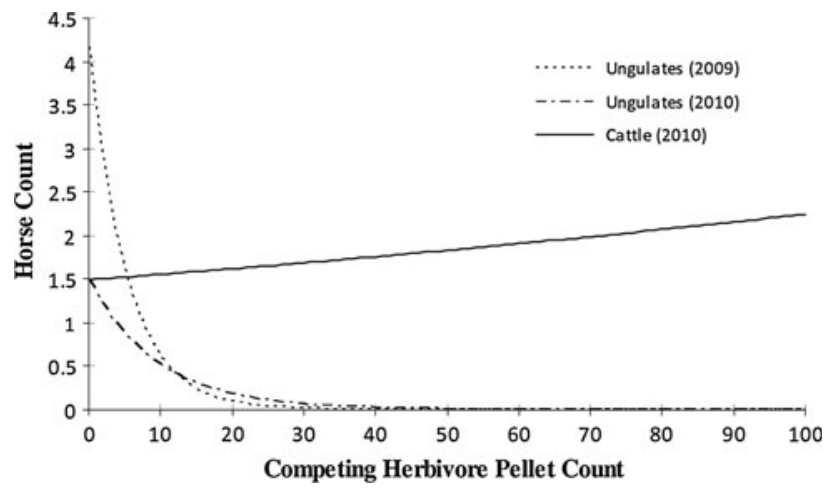

Fig. 3 Horse count models demonstrating the relationship between horse abundance in 2009 and 2010, as influenced by the abundance of competing herbivores. Functions were developed with $\beta$ coefficients derived from the best model using ZIP regression, with other variables not included held constant

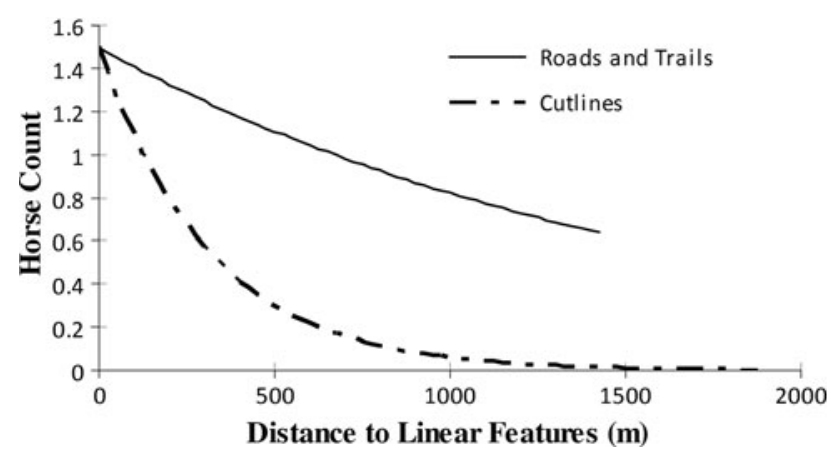

Fig. 4 Horse count models demonstrating the relationship between horse abundance in 2010 and the disturbance variables distance to roads and trails or distance to cutlines. Functions were developed with $\beta$ coefficients derived from the best model using ZIP regression, with other variables not included held constant

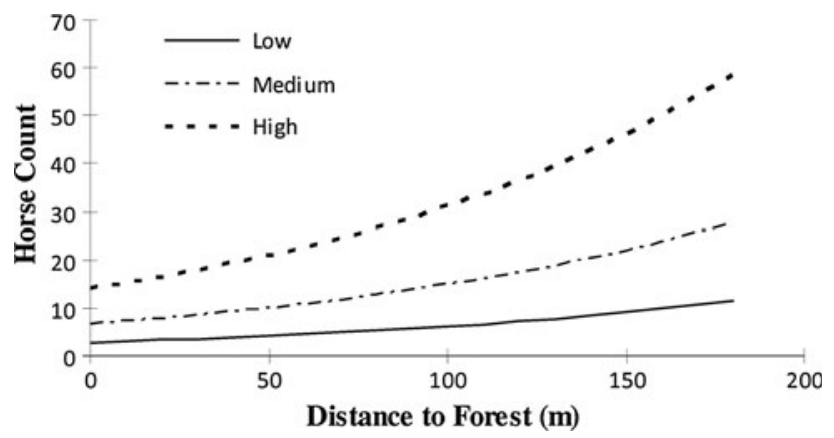

Fig. 5 Horse count models demonstrating the relationship between horse abundance in 2010 and the thermal variables of increasing distance to forest, as further influenced by three levels (low, medium and high) of solar radiation. Functions were developed with $\beta$ coefficients derived from the best model using ZIP regression, with other variables not included held constant

with people (Laliberte and Ripple 2004), but once away from these areas may have preferred to spend time near small secondary trails for use as travel routes (Trombulak and Frissel 2000). This conclusion is further supported by the positive use of cutlines by horses during 2010. Cutlines could serve to increase the mobility of horses (Trombulak and Frissel 2000), particularly in an upland landscape that is otherwise largely forested. Linear features, though relatively small in area, were also unique in that they consisted of previously disturbed ground now dominated by herbaceous vegetation. Thus, linear corridors may provide an expansion, albeit small, of preferred grassland habitat for horses. Overall, these results support our hypotheses regarding the role of corridors in regulating horse use, but further studies are warranted to more fully understand the complex role of disturbances and linear corridors on horse use within these landscapes.

Horse presence and abundance in relation to primary water sources exhibited divergent responses between years. In 2009, horses used areas farther from water, while the opposite response (although weaker) was evident in 2010. This divergence may be due to differences in precipitation between years, as increased rainfall in June 2009 may have increased water availability away from "primary" water sources, allowing horses to spend more time away from these waterways. In 2010, observations of increased horse use near primary water sources may be a response to a $20 \%$ reduction in May-July precipitation that year, as ephemeral water sources are likely to dry up faster under these conditions, forcing horses to spend more time closer to main water sources. In any case, our findings support our hypothesis and other studies suggesting water can play a role in regulating horse use (Stevens 1988), but contrast those of Salter and Hudson (1979) who concluded water was not limiting for habitat use by horses in west central Alberta. Differences between our results and Salter and Hudson (1979) may arise due to differences in study location, with the latter conducted farther north where summer rainfall tends to be greater, as well as differences in the methods of data collection. Salter and Hudson (1979) relied on direct observational data of horse drinking behaviour, which likely limited the spatial extent of their sampling. Finally, horses may also have an affinity for areas near streams due to the ability of adjacent riparian habitats to provide abundant sources of preferred forage, such as found in Wyoming by Crane and others (1997).

As hypothesized, terrain ruggedness was an important deterrent of horse use during both years. These findings are consistent with previous work indicating feral horses avoid complex topography and instead use flat terrain (Ganskopp and Vavra 1987). Within our study area, flatter areas were generally limited to valley bottoms, which also contained the habitats selected by horses (i.e. grasslands and shrublands) and a readily available water supply. Although these habitats were also those with abundant herbage and therefore expected to attract horses (Fleurance and others 
2009), forage biomass did not appear in any of the final models regulating horse occupancy or abundance in this study. These results suggest that forage availability does not regulate horse use patterns in this area, at least during spring and summer.

We hypothesized horses may be negatively impacted by competition from cattle and wild ungulates. Although we anticipated that horses and cattle in particular, as the predominant large herbivores within this ecosystem, would segregate their use in the landscape, this was not supported here. Salter and Hudson (1980) found the majority of primary ranges in their study area had feral horse use during spring prior to cattle entry, a pattern likely to also occur at McLean Creek where cattle do not enter until June. Moreover, spring and early summer use by horses may initially condition vegetation within lowland grasslands, leading to favorable regrowth. This in turn, is known to attract animals to high quality forage (Belsky 1986), a process likely to be further reinforced through the balance of the growing season by repeated cattle and horse use.

A limitation of our study is that faecal counts were conducted in late July and are therefore only representative of spring and early summer herbivore use. Although our forage utilisation assessments within preferred grasslands averaged an acceptable $44 \%$ by late July after $2-3$ months of summer grazing, this value is likely to increase into late summer and fall within primary grassland habitats. Given that cattle typically graze these areas into late September and feral horses are resident year round, continued forage use for the balance of the growing season is likely to result in much greater levels of accumulated use within these areas, and likely account for the decline in range health observed in many grasslands of the region (Michalsky 2010). Primary rangelands within the study area are periodically assessed by provincial rangeland management staff for vegetation composition and evidence of grassland degradation, including litter loss, soil erosion and weed invasion.

The negative response in horse abundance relative to wild ungulates may be explained through several mechanisms. The simplest explanation is that this relationship is a reflection of horses and wild ungulates preferring different habitats, specifically grasslands and woodlands, respectively. Previous work has shown that horses and wild ungulates utilise different habitats due to contrasting dietary requirements (Hubbard and Hansen 1976; McInnis and Vavra 1987). However, an alternative and perhaps more likely explanation is that horses and ungulates may exhibit mutual avoidance across the landscape in an attempt to avoid competition, in effect displacing native ungulates from habitats they normally would use. Moreover, the similar use of habitats by horses and cattle may result in displacement of wild ungulates by both horses and cattle.
Previous study has shown that when livestock move into a region, wild ungulates such as mule deer move into less preferred habitats (Kie and others 1991; Loft and others 1991; Stewart and others 2002). It is also possible that the observed extent of segregation in habitat use between feral horses and wild ungulates may be overestimated based on our method of using faecal counts to assess ungulate presence. For example, elk have been found to defecate where they bed rather than where they graze (Collins and Urness 1981, 1983), thereby overestimating elk use of bedding sites such as forest, and underestimating use of foraging sites. Nevertheless, the observed segregation documented here between feral horses and wild ungulates during summer is noteworthy, with further study needed to evaluate the mechanisms regulating this relationship.

Finally, we note that the increased number of factors affecting feral horse use in 2010 (i.e. disturbance and thermal factors, along with water distance, ruggedness and wild ungulate abundance) explained more than twice the variation in horse use as the year prior (22.6 vs. $10.2 \%$ ) and may reflect the larger number of plots examined during the second year. Although the total variation in horse use explained in this investigation is consistent with other landscape-level investigations of large herbivore behaviour, our results also indicate that considerable variation in horse presence and abundance remains unaccounted for. As an example, the type of human recreational activities (i.e. foot traffic VS motorized traffic) could have different impacts on horse presence and use.

\section{Management Implications}

Our study indicates that feral horses preferred areas that were less rugged, farther from forest, near linear travel corridors likely to receive little human traffic, and closer to water, though only during periods of low precipitation. Information on these characteristics should allow land managers to determine how likely horses are to use specific areas of the landscape, as well as establish maximum horse carrying capacities in combination with other land uses, including cattle grazing.

Strong overlap in habitat use between horses and cattle is likely to lead to increased competition for forage. Although feral horses are currently present in smaller numbers than cattle, their increased body size and yearlong occupation of the region may result in a similar effective stocking rate and impact on preferred habitats to that of cattle. Combined use by cattle and horses is problematic should they exceed the carrying capacity of grasslands, and future management actions may be needed to reduce range use and improve range health. Three possible options to counteract this include: (1) reducing the 
number of cattle, (2) reducing the number of horses through increased horse removals, or (3) increasing efforts to reverse shrub encroachment to restore grasslands previously lost. Reducing cattle stocking rates is unlikely given previous declines in allowable stocking and Alberta's commitment to maintain 1977 stocking levels (Government of Alberta 1984). Similarly, it is unlikely that sporadic horse captures will contain the growth of feral horse populations. While burning of shrublands can increase the area of open grassland in the short term, this action requires continual retreatment (Bork and others 1996), and may simply postpone the need to make a decision on establishing sustainable population sizes of all herbivores. Managing the combined stocking of cattle and horses to conserve native grasslands and their range health is important, but is also associated with significant social challenges, including an increasing public concern for the status and welfare of feral horse populations. It is less clear the extent to which conflict may exist between horses and wild ungulates, including whether horses, either alone or in combination with cattle, are displacing ungulates from preferred habitats. Regardless, the population size and expected level of forage utilisation associated with wild ungulates must be considered when determining sustainable population sizes of all herbivores in the region.

While the RSPFs and count models developed in this study provide important insight on horse habitat selection across this region of the RMFR, several aspects of horse habitat behaviour remain unresolved. This includes the role of forage availability in regulating horse use during other times of the year, such as fall and winter following maximum forage depletion. In addition, it would be beneficial to quantify specific levels of forage utilisation associated with feral horses and cattle to more fully understand how each ungulate affects range health and sustainability. Ultimately, this information will aid resource managers in determining critical habitats based on horse use patterns.

Acknowledgments Funding for this project was provided by a Ministerial Grant to E. W. Bork from Alberta Sustainable Resource Development, the University of Alberta, the Rocky Mountain Forest Range Association, and an ACA-Biodiversity Challenge Grant to T. Girard. We are grateful to Craig DeMaere, Alicia Entem and Michael Girard for their contributions to the project, and to Drs. Robert Hudson, Barry Irving and Evelyn Merrill, all of whom provided input on an earlier draft of the manuscript.

\section{References}

Barry SC, Welsh AH (2002) Generalized additive modelling and zero inflated count data. Ecol Model 157:179-188

Belsky AJ (1986) Does herbivory benefit plants? A review of the evidence. Am Nat 127(6):870-892

Bork EW, Adams BW, Willms WD (1996) Prescribed burning of bog birch. Rangelands 18(1):4-7
Burkinshaw AM, Bork EW (2009) Shrub encroachment impacts the potential for multiple use conflicts on public land. Environ Manag 44(3):493-504

Cameron AC, Windmeijer FAG (1997) An r-squared measure of goodness of fit for some common nonlinear regression models. J Econom 77:329-342

Collins WB, Urness PJ (1981) Habitat preferences of mule deer by pellet-group distributions. J Wildl Manag 45(4):969-972

Collins WB, Urness PJ (1983) Feeding behaviour and habitat selection of mule deer and elk on northern Utah summer range. J Wildl Manag 47(3):646-663

Crane KK, Smith MA, Reynolds D (1997) Habitat selection patterns of feral horses in southcentral Wyoming. J Range Manag 50(4):3 74-380

Environment Canada (2010) Canadian climate normals 1971-2000. http://www.climate.weatheroffice.gc.ca/climate_normals/results_ e.html?StnID=2386\&autofwd=1. Accessed 15 Oct 2010

Fleurance G, Fritz H, Duncan P, Gordon IJ, Edouard N, Vial C (2009) Instantaneous intake rate in horses of different body sizes: influence of sward biomass and fibrousness. Appl Anim Behav Sci 117:84-92

Ganskopp D, Vavra M (1987) Slope use by cattle, feral horses, deer, and bighorn sheep. Northwest Sci 61(2):74-81

Government of Alberta (1984) A policy for the resource management of the eastern slopes. Revised 1984. ENR number T/38. International standard book number 0-85499-067-7. Edmonton

Government of Alberta (2010) C5-forest management plan, 2006-2026. http://www.srd.alberta.ca/ManagingPrograms/ForestManagement/ ForestManagementPlanning/ForestManagementPlans/documents/ ForestManagementUnitC5/FMU-C5-FMP.pdf. Accessed 15 Feb 2011

Government of Alberta (2011) Feral horses. http://www.srd.alberta. $\mathrm{ca} /$ LandsForests/LandManagement/FeralHorses/Default.aspx. Accessed 10 Sept 2011

Holechek JL, Pieper D, Herbel CH (2004) Range management: principles and practices, 5th edn. Pearson Education Inc, Upper Saddle River pp 607

Hubbard RE, Hansen RM (1976) Diets of wild horses, cattle, and mule deer in Piceance basin, Colorado. J Range Manag 29(5): 389-392

Janis C (1976) The evolutionary strategy of the equidae and the origins of rumen and cecal digestion. Evolution 30(4):757-774

Kauffman J (2011) Interactions between cattle grazing and forestry on Alberta's public lands. MSc Thesis. University of Alberta, pp 206

Kie JG, Evans CJ, Loft ER, Menke JW (1991) Foraging behaviour by mule deer: the influence of cattle grazing. J Wildl Manag 55(4): $665-674$

Knopff KH (2010) Cougar predation in a multi-prey system in westcentral Alberta, PhD. Dissertation. University of Alberta, Edmonton pp 294

Kruger K, Flauger B (2008) Social feeding decisions in horses (Equus callabus). Behav Process 78:76-83

Kumar L, Skidmore AK, Knowles E (1997) Modelling topographic variation in solar radiation in a GIS environment. Int J Geogr Inf Sci 11(5):475-497

Laliberte AS, Ripple WJ (2004) Range contractions of North American carnivores and ungulates. Bioscience 54:123-138

Lever C (1985) Naturalized mammals of the world. Longman Group Ltd, New York pp 487

Loft ER, Menke JW, Kie JG (1991) Habitat shifts by mule deer: the influence of cattle grazing. J Wildl Manag 55(1):16-25

Manly BFJ, McDonald LL, Thomas DL, McDonald TL, Erickson WP (2002) Resource selection by animals: statistical design and analysis for field studies. Kluwer Academic Publishers, Dordrecht pp 221 
McInnis ML, Vavra M (1987) Dietary relationships among feral horses, cattle, and pronghorn in southeastern Oregon. J Range Manag 40(1):60-66

Michalsky S (2010) Grazing inventory for management of the Mclean Creek grazing allotment. Prepared for the Rocky Mountain Forest Range Association, Paskwa Consultants Ltd, London

Mysterud A, Østbye E (1999) Cover as a habitat element for temperate ungulates: effects on habitat selection and demography. Wildl Soc Bull 27(2):385-394

Natural Regions Committee (2006) Natural regions and subregions of Alberta. Compiled by Downing DJ, Pettapieve WW. Government of Alberta. Pub. no. T/852, pp 264

Nielsen SE, Johnson CJ, Heard DC, Boyce MS (2005) Can models of presence-absence be used to scale abundance? Two case studies considering extremes in life history. Ecography 28(2):197-208

Riley SJ, DeGloria SD, Elliot R (1999) A terrain ruggedness index that quantifies topographic heterogeneity. Intermt J Sci 5:23-27

Salter RE, Hudson RJ (1979) Feeding ecology of feral horses in western Alberta. J Range Manag 32(3):221-225

Salter RE, Hudson RJ (1980) Range relationships of feral horses with wild ungulates and cattle in western Alberta. J Range Manag 33(4):266-271

SAS Institute Inc (2011) SAS/ETS ${ }^{\circledR} 9.22$ user's guide. http://support. sas.com/documentation/cdl/en/etsug/63348/HTML/default/viewer. htm\#etsug_countreg_sect034.htm. Accessed 1 Oct 2011

Shingu Y, Kondo S, Hata H (2010) Differences in grazing behaviour of horses and cattle at the feeding station scale on woodland pasture. Anim Sci J 81:384-392
Singer B (2005) A brief history of the horse in America. Canadian geographic. http://www.geochallenge.ca/magazine/ma05/indepth/. Accessed 13 Nov 2009

Stevens EF (1988) Contests between bands of feral horses for access to fresh water: the resident wins. Anim Behav 36(6):1851-1853

Stewart KM, Bowyer RT, Kie JG, Cimon NJ, Johnson BK (2002) Temporospatial distributions of elk, mule deer, and cattle: resource partitioning and competitive displacement. J Mammal 83(1):229-244

Trombulak SC, Frissel CA (2000) Review of ecological effects of roads on terrestrial and aquatic communities. Conserv Biol 14(1):18-30

Van Beest FM, Mysterud A, Leo LE, Milner JM (2010) Forage quantity, quality and depletion as scale-dependent mechanisms driving habitat selection of a large browsing herbivore. J Anim Ecol 79:910-922

Vaudor L, Lamouroux N, Olivier JM (2011) Comparing distribution models for small samples of overdispersed counts of freshwater fish. Acta Oecol 37:170-178

Willms WD, Smoliak S, Dormaar JF (1985) Effects of stocking rate on rough fescue grassland vegetation. J Range Manag 38(3):220-225

Willoughby MG, Alexander MJ, Adams BW (2005) Range plant community types and carrying capacity for the montane subregion. 6th Approx. Pub. T/071. Alberta Sustainable Resource Development, Public Lands Division, Edmonton

Windmeijer FAG (1995) Goodness-of-fit measures in binary choice models. Econ Rev 14:101-116 